\title{
Cardiovascular surgery in Jehovah's Witness patients: The role of preoperative optimization
}

\author{
Akiko Tanaka, MD, PhD, ${ }^{\mathrm{a}}$ Takeyoshi Ota, MD, PhD, ${ }^{\mathrm{a}}$ Nir Uriel, MD, MSc, ${ }^{\mathrm{b}}$ Zewditu Asfaw, MD, ${ }^{\mathrm{a}}$ \\ David Onsager, MD, ${ }^{a}$ Vassyl A. Lonchyna, MD, ${ }^{a}$ and Valluvan Jeevanandam, MD $^{a}$
}

\begin{abstract}
Objective: We aimed to identify factors associated with adverse outcomes in Jehovah's Witness patients undergoing complex cardiovascular surgery and to validate our preoperative optimization protocol.

Methods: We retrospectively reviewed 144 Jehovah's Witnesses who underwent cardiovascular surgery between 1999 and 2014. We excluded 7 salvage cases. The operative procedures included 56 coronary artery bypass graft surgeries, 43 valve procedures, 13 ventricular assist device implantations, 11 heart transplantations, 9 aortic surgeries, and 5 congenital defect repairs. Our preoperative optimization protocol for Jehovah's Witnesses includes discontinuing antiplatelets and adding iron/vitamin or erythropoietin to achieve a target hemoglobin greater than $12 \mathrm{~g} / \mathrm{dL}$. We evaluated the risk factors for postoperative mortality and composite outcomes (mortality, myocardial infarction, stroke, acute kidney injury, heart failure, sternal wound infection), and compared the outcomes of optimized patients with a preoperative hemoglobin level greater than $12 \mathrm{~g} / \mathrm{dL}(\mathrm{n}=93)$ versus unoptimized patients with a preoperative hemoglobin level less than $12 \mathrm{~g} / \mathrm{dL}(\mathrm{n}=44)$.
\end{abstract}

Results: Preoperative and intraoperative demographics in the optimized and unoptimized groups were similar except for preoperative hemoglobin levels, renal dysfunction (optimized $=25 / 93[26.9 \%]$, unoptimized $=26 / 44[59.1 \%]$, $P<.001$ ), and emergency/urgent cases (optimized $=20 / 93 \quad[21.5 \%]$, unoptimized $=17 / 44[38.6 \%], P=.035$ ). The mean preoperative, intraoperative nadir, and discharge hemoglobin levels of the entire cohort were $12.7 \pm 1.7 \mathrm{~g} / \mathrm{dL}$, $9.5 \pm 2.6 \mathrm{~g} / \mathrm{dL}$, and $9.7 \pm 1.8 \mathrm{~g} / \mathrm{dL}$, respectively. Hospital mortality was 9 of 137 patients $(6.6 \%)$ (optimized $=2 / 93[2.2 \%]$, unoptimized $=7 / 44[15.9 \%]$, $P=.002$ ), and composite outcomes were observed in 44 of 137 patients $(32.1 \%)$ (optimized $=21 / 93[22.6 \%]$, unoptimized $=22 / 44 \quad[50.0 \%]$, $P=.001)$. The Youden index identified a cutoff value of the preoperative hemoglobin of $11.7 \mathrm{~g} / \mathrm{dL}$ for mortality (area under curve, 0.719 ; sensitivity, $77.8 \%$; specificity, $76.0 \%$ ). Multivariate analysis identified a suboptimal preoperative hemoglobin $(<12 \mathrm{~g} / \mathrm{dL})$ as the only important independent factor associated with mortality (odds ratio, 5.64; 95\% confidence interval, 1.14-42.18) and composite outcomes (odds ratio, 2.49; 95\% confidence interval, 1.06-5.88).

Conclusions: Complex cardiovascular surgery in Jehovah's Witnesses was associated with acceptable surgical outcomes, especially if they electively completed optimization. Our Jehovah's Witnesses' optimization protocol targeting a hemoglobin level greater than $12 \mathrm{~g} / \mathrm{dL}$ seemed to be effective in reducing adverse events at The University of Chicago Medicine. (J Thorac Cardiovasc Surg 2015;150:976-83)

\begin{tabular}{|lcccccc|}
\hline Preoperative factors & \multicolumn{3}{c}{ Univariate } & \multicolumn{4}{c|}{ Multivariate } \\
\cline { 2 - 7 } & OR & $95 \% \mathrm{Cl}$ & P value & OR & $95 \% \mathrm{Cl}$ & P value \\
\hline Age>65-year-old & 2.16 & $1.03-4.50$ & .039 & 2.20 & $0.97-5.14$ & .059 \\
Hb <12.0g/dL & 3.43 & $1.60-7.37$ & .001 & 2.49 & $1.06-5.88$ & .035 \\
eGFR<60mL/min/1.73m & 3.13 & $1.48-6.63$ & .002 & 2.06 & $0.89-4.82$ & .092 \\
2 & & & & & & \\
NYHA class IV & 2.83 & $1.34-5.96$ & .005 & 1.93 & $0.75-4.93$ & .172 \\
IABP support & 2.65 & $1.07-6.51$ & .031 & 1.40 & $0.47-4.10$ & .543 \\
Emergent/Urgent & 3.32 & $1.54-7.17$ & .002 & 2.24 & $0.89-5.62$ & .086 \\
\hline
\end{tabular}

Predictors of significant adverse events after complex cardiovascular surgery in Jehovah's Witness patients.

\section{Central Message}

Preoperative optimization with a hemoglobin level greater than $12 \mathrm{~g} / \mathrm{dL}$ is important for bloodless cardiovascular surgery in Jehovah's Witness patients.

\section{Perspective}

Meticulous perioperative protocol is required to perform safe bloodless cardiovascular surgery in Jehovah's Witness patients. Elective optimization to achieve a preoperative hemoglobin level greater than $12 \mathrm{~g} / \mathrm{dL}$ by iron/ vitamin supplementation and erythropoietin use may be key to avoid excess postoperative significant adverse events.

See Editorial Commentary page 984.
From the a Department of Surgery, Section of Cardiac and Thoracic Surgery, The University of Chicago Medicine, Chicago, Ill; and ${ }^{\mathrm{b}}$ Department of Medicine, Section of Cardiology, The University of Chicago Medicine, Chicago, Ill.

Read at the 95th Annual Meeting of The American Association for Thoracic Surgery, Seattle, Washington, April 25-29, 2015.

Received for publication March 9, 2015; revisions received June 4, 2015; accepted for publication June 17, 2015; available ahead of print July 23, 2015.

\footnotetext{
Address for reprints: Valluvan Jeevanandam, MD, Department of Surgery, Section of Cardiac and Thoracic Surgery, The University of Chicago, 5841 S. Maryland Ave, MC5040, Chicago, IL 60637 (E-mail: jeevan@uchicago.edu). $0022-5223 / \$ 36.00$

Copyright (C) 2015 by The American Association for Thoracic Surgery http://dx.doi.org/10.1016/j.jtcvs.2015.06.059
} 

Abbreviations and Acronyms
AUC = area under the curve
$\mathrm{CPB}=$ cardiopulmonary bypass
eGFR = estimated glomerular filtration rate
IABP $=$ intra-aortic balloon pump
IQR = interquartile range
LVAD $=$ left ventricular assist device
NYHA $=$ New York Heart Association

\section{Supplemental material is available online.}

The Jehovah's Witnesses do not accept transfusions of whole blood, packed red blood cells, plasmas, or platelets because of their belief that blood transfusions are prohibited by certain Bible passages. ${ }^{1}$ Highly complex cardiovascular procedures are not offered to patients at most centers because of the high risk of mortality and morbidity if massive blood loss occurs and transfusions are refused.

Because there are so few surgical teams willing to perform complex cardiovascular procedures on Jehovah's Witness patients, there is a paucity of literature detailing their perioperative care and outcomes. At The University of Chicago Medicine, in addition to meticulous operative techniques, we developed a perioperative management protocol of optimization of Jehovah's Witness patients (Table E1). This is the first single-center study to report the surgical outcomes of Jehovah's Witnesses undergoing the whole spectrum of complex cardiovascular surgery, including left ventricular assist device (LVAD) implantation, heart transplantation, and aortic surgery. In this study, we sought to determine the preoperative factors associated with adverse outcomes and to evaluate the feasibility of a preoperative optimization protocol.

\section{MATERIALS AND METHODS}

The study was approved by the University of Chicago's Institutional Review Board. Between October 1999 and December 2014, 144 patients who were identified as Jehovah's Witnesses with documented refusal of blood products underwent complex cardiovascular surgery. Our philosophy has been to offer surgery to all Jehovah's Witnesses who present to our surgical service with appropriate indications for surgery. Patients who presented in refractory cardiogenic shock requiring resuscitation and underwent salvage surgery $(n=7)$ were excluded from the study. Thus, 137 patients were enrolled in this study. The baseline demographics, intraoperative data, and postoperative outcomes for these patients were retrospectively collected from patient charts and the institutional cardiac surgery outcomes database. The estimated glomerular filtration rate (eGFR) was calculated from the serum creatinine levels using the Modification of Diet in Renal Disease Formula. ${ }^{2}$ Chronic kidney disease was defined as eGFR less than $60 \mathrm{~mL} / \mathrm{min} / 1.73 \mathrm{~m}^{2}$. Postoperative acute kidney injury was defined as an increase in serum creatinine 2.0 or more times the baseline, a decrease in eGFR of $50 \%$ or more, or urine output less than $0.5 \mathrm{~mL} / \mathrm{kg} / \mathrm{h}$ for 12 hours.

\section{Preoperative Management}

Informed consent was obtained from the Jehovah's Witness patient with emphasis on the consequences and risks of transfusion denial. The patient's right of refusal of blood products is rigidly honored by the surgeons and hospital staff. The acceptance of albumin, immunoglobulins, and transplantation is a personal decision of the patient ${ }^{1}$ and documented on the consent form.

We developed a preoperative optimization protocol for Jehovah's Witnesses, which includes supplementation with oral (intravenous) iron or vitamin (vitamin B12, folic acid) and subcutaneous (intravenous) erythropoietin to increase preoperative hemoglobin greater than $12 \mathrm{~g} / \mathrm{dL}$. This target level was determined on the basis of the hemodilution during cardiopulmonary bypass (CPB). To avoid adverse effects of a low hematocrit during CPB, we aimed for a hematocrit level of $27 \%$ to $28 \%$ at the initiation of CPB and a nadir hematocrit greater than $25 \% .{ }^{4}$ The ideal minimal preoperative hemoglobin level of $12 \mathrm{~g} / \mathrm{dL}$ was obtained from the volume concentration formula, using the circuit priming volume of $1000 \mathrm{~mL}$ and average patient weight of $85 \mathrm{~kg}$.

Antiplatelet agents are discontinued at least 5 days preoperatively (clopidogrel for 10 days). Any supplement, food, or medication that may increase the risk of bleeding (ie, vitamin E, fish oil, turmeric, and ginger) is also withheld. In addition, procedures such as cardiac catheterization are scheduled several weeks before surgery to allow the patient to recover from the renal toxicity of the contrast and any blood loss.

\section{Intraoperative Management}

Standard anesthesia, anticoagulation during CPB, and myocardial protection are used. Volume resuscitation is primarily with crystalloid. Albumin is administered only to those patients who agreed to its use. The $\mathrm{CPB}$ circuit is primed using the retrograde autologous priming technique, and ultrafiltration is used throughout bypass to reduce hemodilution. ${ }^{5}$ The use of pump suckers is preferred for platelet and coagulation factor preservation, ${ }^{6}$ and the Cell Saver (Haemonetics Corp, Braintree, Mass) is avoided as much as possible during CPB. Autologous whole blood is sequestrated in selected patients at the initiation of CPB. The blood is always kept in continuity to the patient and is returned at the end of CPB before disconnection. Core body temperature is cooled to $34^{\circ} \mathrm{C}$ and fully rewarmed to $37^{\circ} \mathrm{C}$ before weaning off bypass. At the end of $\mathrm{CPB}$, the remaining volume in the reservoir and $\mathrm{CPB}$ circuit is hemoconcentrated and returned to the patient before removal of the aortic cannula. Heparin is reversed with protamine at a ratio of $1: 1$.

Meticulous surgical technique and hemostasis are imperative in each patient. For instance, during LVAD implantation, the outflow graft to aorta anastomosis has a polytetrafluoroethylene "gasket" incorporated in the suture line to minimize blood loss. Topical hemostatic agents are used as the first-line hemostatic adjuncts: resorbable synthetic hemostatic bone putty (eg, Hemasorb, Abyrx Inc, Irvington, NY), synthetic sealant (eg, Coseal, Baxter Healthcare Corp, Deerfield, Ill), oxidized cellulose hemostat (eg, Surgicel, Ethicon US, LCC, Cincinnati, Ohio), and gelatin foam/sponges (eg, Gelfoam, Pfizer Inc, New York, NY). Blood derivatives such as topical fibrinogen and thrombin are administered, as needed, only to patients who preoperatively agree to their use. Systemic hemostatic agents used are epsilon-aminocaproic acid and factor VIIa (NovoSeven RT, Novo Nordisk Inc, Plainsboro, NJ), which are nonblood derivative recombinant products. Aprotinin (Trasylol, Bayer HealthCare, Whippany, NJ) was used until its withdrawal from the market in 2008 . 
TABLE 1. Preoperative patient demographics

\begin{tabular}{|c|c|c|c|c|}
\hline Characteristics & Overall $(n=137)$ & Optimized $(n=93)$ & Unoptimized $(n=44)$ & $P$ value \\
\hline Age, y & $64(55-73)$ & $62(54-71)$ & $66(58-75)$ & .103 \\
\hline Male & $77(56.2 \%)$ & $57(61.3 \%)$ & $20(45.5 \%)$ & .081 \\
\hline $\operatorname{BSA}\left(\mathrm{m}^{2}\right)$ & $2.0(1.8-2.2)$ & $2.0(1.8-2.2)$ & $2.0(1.9-2.2)$ & .972 \\
\hline BMI $\left(\mathrm{kg} / \mathrm{m}^{2}\right)$ & $29.0(25.2-34.9)$ & $28.5(25.0-35.5)$ & $30.5(25.8-34.8)$ & .344 \\
\hline \multicolumn{5}{|l|}{ Hemoglobin $(\mathrm{g} / \mathrm{dL})$} \\
\hline At the initial clinic visit & $12.4(11.1-13.6)$ & $13.2(12.1-14.4)$ & $10.9(9.7-11.9)$ & $<.001$ \\
\hline At the time of surgery & $12.7(11.7-13.6)$ & $13.3(12.6-14.4)$ & $11.2(9.9-11.5)$ & $<.001$ \\
\hline Diabetes mellitus & $47(34.3 \%)$ & $27(29.0 \%)$ & $20(45.5 \%)$ & .059 \\
\hline Chronic lung disease & $34(25.2 \%)$ & $23(25.3 \%)$ & $11(25.0 \%)$ & .973 \\
\hline Hypertension & $101(73.7 \%)$ & $66(71.0 \%)$ & $35(79.6 \%)$ & .287 \\
\hline Hyperlipidemia & $88(64.2 \%)$ & $57(61.3 \%)$ & $31(70.5 \%)$ & .296 \\
\hline Cerebrovascular disease & $12(8.8 \%)$ & $7(7.5 \%)$ & $5(11.4 \%)$ & .458 \\
\hline Chronic kidney disease & $51(37.2 \%)$ & $25(26.9 \%)$ & $26(59.1 \%)$ & $<.001$ \\
\hline Renal failure on dialysis & $9(6.6 \%)$ & $2(2.2 \%)$ & $7(15.9 \%)$ & .005 \\
\hline Severe PAH & $31(22.6 \%)$ & $20(21.5 \%)$ & $11(25.0 \%)$ & .598 \\
\hline NYHA class IV & $53(38.7 \%)$ & $34(36.6 \%)$ & $19(43.1 \%)$ & .457 \\
\hline Inotrope support & $20(14.6 \%)$ & $12(12.9 \%)$ & $8(18.2 \%)$ & .225 \\
\hline IABP support & $24(17.5 \%)$ & $13(14.0 \%)$ & $11(25.0 \%)$ & .113 \\
\hline LVEF (\%) & $45(25-60)$ & $48(25-60)$ & $45(24-60)$ & 1.000 \\
\hline Previous cardiac surgery & $25(18.2 \%)$ & $20(21.5 \%)$ & $5(11.4 \%)$ & .151 \\
\hline Active IE & $3(2.2 \%)$ & $2(2.2 \%)$ & $1(2.3 \%)$ & .640 \\
\hline Emergency/urgent & $37(27.0 \%)$ & $20(21.5 \%)$ & $17(38.6 \%)$ & .035 \\
\hline
\end{tabular}

Data are presented as median (IQR) or $\mathrm{n}(\%)$. PAH is systolic pulmonary artery pressure $>55 \mathrm{~mm} \mathrm{Hg}$. Chronic kidney disease is eGFR $<60 \mathrm{~mL} / \mathrm{min} / 1.73 \mathrm{~m}{ }^{2} . B M I$, Body mass index; BSA, body surface area; IABP, intra-aortic balloon pump; IE, infective endocarditis; $L V E F$, left ventricular ejection fraction; NYHA, New York Heart Association; $P A H$, pulmonary artery hypertension.

\section{Postoperative Management}

The patients are maintained at normothermia, and hypertension is avoided. Routine blood tests are eliminated and obtained only as clinically indicated. Pediatric blood tubes are used for sample collection, and a coagulation profile is tested only in patients receiving anticoagulation therapy or presenting with bleeding issues. Patients are continued on intravenous iron and vitamin supplements. Erythropoietin also is used during the postoperative period if the first postoperative hemoglobin level is less than $11 \mathrm{~g} / \mathrm{dL}$. To maximize systemic oxygen delivery, Jehovah's Witness patients are maintained on hemodynamic support (ie, inotropes, intraaortic balloon pump [IABP], and mechanical ventilator support) for a longer period when compared with non-Jehovah's Witnesses.

\section{Statistical Analysis}

Continuous data are reported as mean \pm 1 standard deviation for normally distributed data or median plus interquartile range (IQR) for skewed data. Categoric variables are expressed as number or fractions of patients. Comparisons between continuous variables were performed using Student $t$ test for parametric data or the Wilcoxon rank-sum test for nonparametric data. Categoric variables were compared using a chi-square test or Fisher exact test for expected cell counts less than 5. Preoperative demographics and intraoperative/postoperative outcomes in patients with preoperative hemoglobin greater than $12 \mathrm{~g} / \mathrm{dL}$ (optimized group) and hemoglobin less than $12 \mathrm{~g} / \mathrm{dL}$ (unoptimized group) were compared to evaluate the efficacy of our protocol. Univariate analysis was performed on all preoperative variables (ie, advanced age, female sex, obesity, diabetes mellitus, chronic lung disease, chronic kidney injury, pulmonary hypertension, preoperative use of IABP, New York Heart Association [NYHA] class IV, cerebrovascular disease, low left ventricular ejection fraction $<40 \%$, emergency/urgent cases, resternotomy, and hemoglobin $<12 \mathrm{~g} / \mathrm{dL}$ ) to detect potential risk factors for mortality and postoperative adverse events. Only variables with a $P$ value less than .1 on univariate analysis were retained for the multivariate regression tests to identify significant independent factors associated with adverse events. Composite outcomes of significant postoperative significant adverse events (mortality, postoperative myocardial infarction, stroke, acute kidney injury, heart failure newly requiring IABP, and deep sternal wound infection) were also evaluated to ensure the statistical efficiency. Subanalysis was also performed in nonurgent patients who presented to our clinic with a hemoglobin level of $12 \mathrm{~g} / \mathrm{dL}$ to identify the factors associated with failure to obtain the optimal hemoglobin level of $12 \mathrm{~g} / \mathrm{dL}$ at the time of surgery. For all analyses, 2-sided tests were used. The sensitivity and specificity of the preoperative hemoglobin as an indicator of mortality and morbidity were determined from the cutoff values. Receiver operating characteristic curves and the area under the curve (AUC) for the receiver operating characteristic curve were obtained by plotting the sensitivity against the false-positive rate (1-specificity). The Youden index was used to determine the optimal cutoff values of the preoperative hemoglobin level for identification of the surgical risk of mortality (Youden index $=$ sensitivity + specificity -1 ). All statistical analyses were performed using JMP software (SAS Institute Inc, Cary, NC).

\section{RESULTS}

The preoperative patient characteristics of the entire cohort and the optimized and unoptimized groups are summarized in Table 1. Important differences observed between the optimized and unoptimized groups were the median hemoglobin level $(\mathrm{g} / \mathrm{dL})$ at the initial clinic visit (optimized $=13.2$, unoptimized $=10.9$, $P<.001$ ) and at the time of surgery (optimized $=13.3$, unoptimized $=11.2, P<.001)$, the prevalence of chronic kidney disease (optimized $=25$ [26.9\%], 
TABLE 2. Intraoperative patient demographics

\begin{tabular}{|c|c|c|c|c|}
\hline Variables & Overall $(n=137)$ & Optimized $(\mathbf{n}=93)$ & Unoptimized $(n=44)$ & $P$ value \\
\hline \multicolumn{5}{|l|}{ Operative procedures } \\
\hline CABG & $54(39.4 \%)$ & $39(41.9 \%)$ & $15(34.1 \%)$ & .380 \\
\hline CABG + Dor operation & $2(1.5 \%)$ & $1(1.1 \%)$ & $1(2.3 \%)$ & .541 \\
\hline Valve surgery & $32(23.4 \%)$ & $22(23.7 \%)$ & $10(22.7 \%)$ & .905 \\
\hline Valve surgery $+\mathrm{CABG}$ & $11(8.0 \%)$ & $5(5.4 \%)$ & $6(13.6 \%)$ & .097 \\
\hline Aortic surgery & $9(6.6 \%)$ & $7(7.5 \%)$ & $2(4.6 \%)$ & .718 \\
\hline LVAD implantation & $13(9.5 \%)$ & $7(7.5 \%)$ & $6(13.6 \%)$ & .255 \\
\hline Heart transplantation & $11(8.0 \%)$ & $7(7.5 \%)$ & $4(9.1 \%)$ & .745 \\
\hline Congenital defect repair* & $5(3.7 \%)$ & $5(5.4 \%)$ & $0(0 \%)$ & .176 \\
\hline $\mathrm{CPB}$ use & $102(75 \%)$ & $66(71.0 \%)$ & $35(81.4 \%)$ & .196 \\
\hline Aortic crossclamp use & $84(61.8 \%)$ & $57(61.3 \%)$ & $27(62.8 \%)$ & .867 \\
\hline CPB time $(n=102)$ & $141(108-182)$ & $143(110-185)$ & $140(103-171)$ & .315 \\
\hline ACC time $(\min )(\mathrm{n}=84)$ & $114(86-139)$ & $117(90-148)$ & $97(66-132)$ & .053 \\
\hline Intraoperative maximum lactate & $1.3(0.9-1.8)$ & $1.2(0.8-1.7)$ & $1.4(1.0-2.2)$ & .109 \\
\hline \multicolumn{5}{|l|}{ Hemostatic adjuncts use } \\
\hline EACA & $82(59.9 \%)$ & $51(54.8 \%)$ & $31(70.5 \%)$ & .082 \\
\hline Recombinant factor VIII & $4(8.8 \%)$ & $2(7.5 \%)$ & $2(11.4 \%)$ & .593 \\
\hline Aprotinin $(\mathrm{n}=38) \dagger$ & $14(36.8 \%)$ & $10(35.7 \%)$ & $4(40 \%)$ & 1.000 \\
\hline
\end{tabular}

Data are presented as mean \pm standard deviation, median (IQR), or n (\%). ACC, Aortic crossclamp; $C A B G$, coronary artery bypass grafting; $C P B$, cardiopulmonary bypass; $E A C A$, epsilon-aminocaproic acid; $L V A D$, left ventricular assist device. *One patient received pulmonary thromboembolectomy in addition to atrial septal defect closure. $\dagger$ Used before the withdrawal of the product (optimized, $\mathrm{n}=28$; unoptimized, $\mathrm{n}=10$ ).

unoptimized $=26[59.1 \%], P<.001)$, and emergency/ urgent cases (optimized $=20[21.5 \%]$, unoptimized $=17$ $[38.6 \%], P=.035)$.

Intraoperative and postoperative data are summarized in Tables 2 and 3. Blood products were not administered to any patient during the hospital stay. Surgical procedures were not significantly different between the 2 groups. Five patients underwent reoperation: 2 in the optimized group (bleeding $=1$, sternal instability $=1$ ) and 3 in the unoptimized group (bleeding $=1$, hemodynamic instability $=1$, sternal instability $=1$ ). There were 9 $(6.7 \%)$ in-hospital deaths: $2(2.2 \%)$ in the optimized group and $7(15.9 \%)$ in the unoptimized group $(P=.002)$. The causes of deaths are summarized in Table 4 .
The Youden index identified a preoperative hemoglobin cutoff value of $11.7 \mathrm{~g} / \mathrm{dL}$ for in-hospital mortality (AUC $=0.719$, sensitivity $=77.8 \%$, specificity $76.0 \%$ ) and $11.9 \mathrm{~g} / \mathrm{dL}$ for both postoperative acute kidney injury (AUC $=0.729$, sensitivity $=58.6 \%$, specificity $=81.4 \%)$ and prolonged ventilation ( $>48$ hours: $\mathrm{AUC}=0.738$, sensitivity $=88.9 \%$, specificity $=70.4 \%)$. Univariate analysis revealed suboptimal preoperative hemoglobin $(<12 \mathrm{~g} / \mathrm{dL})$, older age, chronic kidney disease, NYHA class IV, and emergency/urgent cases as important factors associated with composite outcomes of significant adverse events (Table 5). Multivariate analysis identified suboptimal hemoglobin $(<12 \mathrm{~g} / \mathrm{dL})$ as the only significant independent factor associated with composite outcomes. In addition, univariate analysis revealed suboptimal

TABLE 3. Postoperative outcomes

\begin{tabular}{|c|c|c|c|c|c|}
\hline Outcomes & Overall $(n=137)$ & Optimized $(\mathbf{n}=93)$ & Unoptimized $(n=44)$ & OR $(95 \%$ CI $)$ & $P$ value \\
\hline Required IABP & $10(7.4 \%)$ & $6(6.5 \%)$ & $4(9.3 \%)$ & $1.45(0.39-5.42)$ & .726 \\
\hline Reexploration for bleeding & $2(1.5 \%)$ & $1(1.1 \%)$ & $1(2.3 \%)$ & $2.14(0.13-35.00)$ & .541 \\
\hline Prolonged ventilation $(>48 \mathrm{~h})$ & $9(6.6 \%)$ & $2(2.2 \%)$ & $7(15.9 \%)$ & $8.61(1.71-43.38)$ & .005 \\
\hline Deep sternal wound infection & $1(0.7 \%)$ & $1(1.1 \%)$ & $0(0 \%)$ & 0 & 1.000 \\
\hline Stroke & $3(2.2 \%)$ & $2(2.2 \%)$ & $1(2.3 \%)$ & $1.06(0.09-12.00)$ & 1.000 \\
\hline Acute kidney injury & $29(21.2 \%)$ & $12(12.9 \%)$ & $17(38.6 \%)$ & $5.60(2.30-13.59)$ & $<.001$ \\
\hline Newly required dialysis & $5(4.1 \%)$ & $2(1.1 \%)$ & $3(6.8 \%)$ & $4.21(0.67-26.39)$ & .129 \\
\hline Atrial fibrillation & $35(25.5 \%)$ & $24(26.8 \%)$ & $11(25.0 \%)$ & $0.96(0.42-2.19)$ & .920 \\
\hline \multicolumn{6}{|l|}{ Hemoglobin $(\mathrm{g} / \mathrm{dL})$} \\
\hline Intraoperative nadir & $8.9(7.8-11.0)$ & $10.2(8.5-11.5)$ & $7.6(6.6-9.2)$ & $1.97(1.51-2.72)$ & $<.001$ \\
\hline Postoperative nadir & $8.9(7.8-10.4)$ & $9.5(8.3-10.8)$ & $7.9(6.9-9.1)$ & $1.43(1.17-1.78)$ & $<.001$ \\
\hline Discharge & $9.8(8.5-10.9)$ & $10.1(8.9-11.0)$ & $8.6(7.7-9.8)$ & $1.48(1.17-1.93)$ & $<.001$ \\
\hline In-hospital death & $9(6.6 \%)$ & $2(2.2 \%)$ & $7(15.9 \%)$ & $8.61(1.71-43.438)$ & .005 \\
\hline Major adverse events & $43(32.1 \%)$ & $21(22.6 \%)$ & $22(50.0 \%)$ & $3.42(1.59-7.37)$ & .001 \\
\hline
\end{tabular}

Data are presented as median (IQR) or n (\%). CI, Confidence interval; IABP, intra-aortic balloon pump; OR, odds ratio. Unoptimized versus optimized. 
TABLE 4. In-hospital mortalities

\begin{tabular}{llcc}
\hline \multicolumn{1}{c}{ Primary diagnosis } & \multicolumn{1}{c}{ Operative mode } & Postoperative nadir Hb (g/dL) & Cause of deaths \\
\hline AMI (day 3) & CABG & 8 & Low output syndrome*, $\dagger$ \\
TGA, post-Mustard repair & OHT $(+$ unexpected BiVAD, IABP) & 11.2 & Primary graft dysfunction \\
AS & AVR & 7.2 & Ventricular fibrillation*, $\dagger$ \\
PTE, post-CABG & Thrombectomy & 11.2 & Pulmonary hypertension \\
AS, MS & AVR + MVR & 5.5 & Sepsis $\dagger$ \\
DCM & VAD implantation & 7.6 & Right ventricular failure*, $\dagger$ \\
CAD, IMR & CABG + MVP + TAP & 8 & Pneumonia $\dagger$ \\
AS, MS, Afib & AVR + MVR + Maze & 7.1 & Pneumonia $\dagger$ \\
Type A aortic dissection & Bentall + Hemiarch replacement & 8.9 & Anaphylaxis \\
\hline
\end{tabular}

$A f i b$, Atrial fibrillation; $A M I$, acute myocardial infarction; $A S$, aortic stenosis; $A V R$, aortic valve replacement; $B i V A D$, biventricular ventricular assist device; $C A B G$, coronary artery bypass grafting; $C A D$, coronary artery disease; $D C M$, dilated cardiomyopathy; $H b$, hemoglobin; IABP, intra-aortic balloon pump; $I M R$, ischemic mitral regurgitation; $M S$, mitral stenosis; $M V P$, mitral valve plasty; $M V R$, mitral valve replacement; $O H T$, orthotopic heart transplant; $P T E$, pulmonary thromboembolism; TAP, tricuspid annuloplasty; $T G A$, transposition of the great arteries; $V A D$, ventricular assist device. ${ }^{*}$ These patients might have had better chance of survival with mechanical circulatory support. $\dagger$ These patients might have had a benefit from blood transfusion.

hemoglobin $(<12 \mathrm{~g} / \mathrm{dL})$, chronic kidney disease, severe pulmonary artery hypertension, and emergency/urgent cases as important factors associated with in-hospital mortality (Table E2). Multivariate analysis identified a hemoglobin level less than $12 \mathrm{~g} / \mathrm{dL}$ as the only significant independent factor associated with mortality (Table 6). Furthermore, suboptimal hemoglobin $(<12 \mathrm{~g} / \mathrm{dL})$ was one of the significant independent factors associated with postoperative prolonged ventilation and acute kidney injury (Tables E2 and E3). Other factors associated with prolonged ventilation and acute kidney injury were obesity and NYHA class IV, and preoperative IABP support, respectively.

TABLE 5. Preoperative risk factors for composite outcomes of significant adverse events

\begin{tabular}{|c|c|c|c|c|c|c|}
\hline \multirow[b]{2}{*}{ Preoperative factors } & \multicolumn{3}{|c|}{ Univariate } & \multicolumn{3}{|c|}{ Multivariate } \\
\hline & OR & $95 \%$ CI & $\begin{array}{c}P \\
\text { value }\end{array}$ & OR & $95 \%$ CI & $\begin{array}{c}P \\
\text { value }\end{array}$ \\
\hline Age $>65 y$ & 2.16 & $1.03-4.50$ & .039 & 2.20 & $0.97-5.14$ & .059 \\
\hline Female & 0.89 & $0.43-1.85$ & .758 & & & \\
\hline $\mathrm{BMI}>30 \mathrm{~kg} / \mathrm{m}^{2}$ & 1.42 & $0.69-2.94$ & .338 & & & \\
\hline $\mathrm{Hb}<12.0 \mathrm{~g} / \mathrm{dL}$ & 3.43 & $1.60-7.37$ & .001 & 2.49 & $1.06-5.88$ & .035 \\
\hline Diabetes mellitus & 1.61 & $0.78-3.34$ & .200 & & & \\
\hline $\begin{array}{l}\text { Cerebrovascular } \\
\text { disease }\end{array}$ & 1.92 & $0.70-5.27$ & .202 & & & \\
\hline Chronic lung disease & 1.03 & $0.45-2.37$ & .942 & & & \\
\hline $\begin{array}{l}\mathrm{eGFR}<60 \mathrm{~mL} / \mathrm{min} / \\
1.73 \mathrm{~m}^{2}\end{array}$ & 3.13 & $1.48-6.63$ & .002 & 2.06 & $0.89-4.82$ & .092 \\
\hline $\mathrm{sPAP}>55 \mathrm{~mm} \mathrm{Hg}$ & 1.83 & $0.80-4.19$ & .150 & & & \\
\hline LVEF $<40 \%$ & 1.67 & $0.80-3.47$ & .171 & & & \\
\hline NYHA IV & 2.83 & $1.34-5.96$ & .005 & 1.93 & $0.75-4.93$ & .172 \\
\hline IABP support & 2.65 & $1.07-6.51$ & .031 & 1.40 & $0.47-4.10$ & .543 \\
\hline Resternotomy & 1.60 & $0.65-3.92$ & .305 & & & \\
\hline Emergency/urgent & 3.32 & $1.54-7.17$ & .002 & 2.24 & $0.89-5.62$ & .086 \\
\hline
\end{tabular}

Subanalysis of 41 nonemergency/urgent patients whose hemoglobin level at the initial clinic visit less than $12 \mathrm{~g} / \mathrm{dL}$ demonstrated those who failed to reach a hemoglobin level of $12 \mathrm{~g} / \mathrm{dL}$ at the time of operation had a tendency of higher prevalence of older age (success $=4 / 17[23.5 \%]$, failure $=14 / 24 \quad[51.9 \%]$, $P=.063$ ) and hemodialysis (success $=7 / 17$ [41.2\%], failure $=18 / 24[66.7 \%], P=.097)$ (Table E4).

The median postoperative 24-hour blood loss in the entire cohort, optimized group, and unoptimized group was 550 $\mathrm{mL}$ (IQR, 385-788 mL), $537 \mathrm{~mL}$ (IQR, 380-292 mL), and $662 \mathrm{~mL}$ (IQR, 390-900 mL), respectively. The median blood loss of the entire cohort during the aprotinin era versus the postwithdrawal era was $674 \mathrm{~mL}(\mathrm{n}=46$;

TABLE 6. Preoperative factors associated with in-hospital mortality

\begin{tabular}{|c|c|c|c|c|c|c|}
\hline \multirow[b]{2}{*}{ Preoperative factors } & \multicolumn{3}{|c|}{ Univariate } & \multicolumn{3}{|c|}{ Multivariate } \\
\hline & OR & $95 \% \mathrm{CI}$ & $\begin{array}{c}P \\
\text { value }\end{array}$ & OR & $95 \% \mathrm{CI}$ & $\begin{array}{c}P \\
\text { value }\end{array}$ \\
\hline Age $>65 y$ & 1.41 & $0.36-5.52$ & .614 & & & \\
\hline Female & 1.03 & $0.26-4.01$ & .968 & & & \\
\hline $\mathrm{BMI}>30 \mathrm{~kg} / \mathrm{m}^{2}$ & 0.879 & $0.23-3.42$ & .852 & & & \\
\hline $\mathrm{Hb}<12.0 \mathrm{~g} / \mathrm{dL}$ & 8.61 & $1.71-43.38$ & .005 & 5.64 & $1.14-42.18$ & .033 \\
\hline Diabetes mellitus & 1.17 & $0.30-4.56$ & .822 & & & \\
\hline $\begin{array}{l}\text { Cerebrovascular } \\
\text { disease }\end{array}$ & 2.00 & $0.38-10.48$ & .404 & & & \\
\hline Chronic lung disease & 1.53 & $0.36-6.49$ & .560 & & & \\
\hline $\begin{array}{l}\mathrm{eGFR}<60 \mathrm{~mL} / \mathrm{min} / \\
1.73 \mathrm{~m}^{2}\end{array}$ & 6.68 & $1.33-33.54$ & .013 & 3.74 & $0.72-28.34$ & .118 \\
\hline On dialysis & 4.94 & $0.86-28.32$ & .109 & & & \\
\hline sPAP $>55 \mathrm{~mm} \mathrm{Hg}$ & 4.90 & $1.23-19.56$ & .015 & 3.42 & $0.70-17.17$ & .126 \\
\hline $\mathrm{LVEF}<40 \%$ & 0.74 & $0.19-2.84$ & .647 & & & \\
\hline NYHA IV & 1.28 & $0.33-5.03$ & .714 & & & \\
\hline IABP support & 0.00 & & .360 & & & \\
\hline Resternotomy & 1.30 & $0.25-6.69$ & .750 & & & \\
\hline Emergency/urgent & 5.14 & $1.46-18.08$ & .009 & 2.58 & $0.53-12.84$ & .234 \\
\hline
\end{tabular}


IQR, 340-900 $\mathrm{mL})$ and $537 \mathrm{~mL}(\mathrm{n}=91, \mathrm{IQR}, 388-718 \mathrm{~mL})$, and no significant difference was observed between the 2 eras $(P=.471)$. In addition, the postoperative mortality rate, acute kidney injury, stroke, and myocardial infarction were similar between the 2 eras (Table E5).

\section{DISCUSSION}

In this study, we demonstrate that complete preoperative optimization leads to excellent results in Jehovah's Witness patients undergoing complex cardiovascular surgery. Our philosophy of care is to offer cardiovascular surgery to any Jehovah's Witness patient who has an indication for surgical treatment. Many surgical centers do not operate on these patients because they are not willing to proceed without the ability to transfuse blood products when the need arises in these complex cardiac cases. Jehovah's Witness patients referred to our surgical service were mostly self-referred because they had been declined a surgical procedure at other centers or by recommendations of other Jehovah's Witnesses or Jehovah's Witness Hospital Liaison Committees. Surgery was performed on every eligible Jehovah's Witness patient who was referred to our service except for 1 with advanced liver cirrhosis who had undergone 4 sternotomies and was in low cardiac output.

Surgeries performed in this series include LVAD implantation $(n=13)$, heart transplantation $(n=11)$, aortic root replacement $(\mathrm{n}=5)$, and aortic root and total arch replacement $(n=1)$. The gravity of the clinical conditions of these patients is reflected in that $38.7 \%$ were in NYHA class IV. In addition, $14.6 \%$ were taking inotropes preoperatively and $17.5 \%$ had preoperative IABP support.

Open surgery in Jehovah's Witness patients was first described by Cooley and associates ${ }^{7}$ in 1964. Several large series have since been reported. ${ }^{8-10}$ Lewis and associates ${ }^{8}$ reported a mortality rate of $7 \%$ to $10 \%$ in 1991 . Mortality rates improved markedly to $1 \%$ to $3 \%$ in 2012 as reported by Vaislic and associates ${ }^{9}$ and Pattakos and associates. ${ }^{10}$ Technical advancements in cardiac surgery during the past 2 decades with an emphasis on major reductions in blood loss ${ }^{11}$ and well-developed blood preservation proto$\mathrm{cols}^{12}$ may have contributed to these improved outcomes. However, Vaislic and associates ${ }^{9}$ declined 122 of 622 patients who were referred to their service, and Pattakos and associates ${ }^{10}$ excluded resternotomy cases, LVAD implantation, and heart transplantation from their study. Thus, results of the studies by Vaislic and colleagues ${ }^{9}$ and Pattakos and colleagues ${ }^{10}$ may have been biased by careful patient selection. Cardiovascular surgery in Jehovah's Witness patients carries an increased risk mainly because of the inability to transfuse blood when the need arises. Four of our 9 patients who died in-hospital (ie, pneumonia in 2, sepsis in 1, and arrhythmia in 1) might have had a better outcome with blood transfusion, and 2 patients (ie, low output syndrome and arrhythmia) might have had a chance of survival with mechanical circulatory support if there were no blood product restrictions. Yet, despite the fact that our patient population had high preoperative risks and underwent complex procedures, we were still able to demonstrate excellent clinical outcomes, especially mortality $(2.2 \%$ in the optimized group and $6.6 \%$ in the unoptimized group). Our results are comparable to the $5.5 \%$ mortality reported by Jassar and associates in $2012,{ }^{12}$ in which complex cases and urgent cases were included. Both our and Jassar and colleagues' data may be the true nonbiased outcomes in Jehovah's Witness patients.

We have developed a perioperative management protocol for Jehovah's Witness. Although preoperative hemoglobin level, chronic kidney injury, and urgent/emergency cases were the only differences found in preoperative demographics between optimized and unoptimized patients, the optimized group clearly demonstrated better outcomes compared with the unoptimized group. Multivariate analysis proved that preoperative hemoglobin less than $12 \mathrm{~g} / \mathrm{dL}$ was the only significant preoperative factor associated with significant adverse events. The results of multivariate analysis along with the cutoff values determined by the Youden index for mortality $(11.7 \mathrm{~g} / \mathrm{dL})$ and 2 complications (acute kidney injury and prolonged ventilation, $11.9 \mathrm{~g} / \mathrm{dL}$ ) validated the feasibility of a minimum preoperative target hemoglobin level of $12 \mathrm{~g} / \mathrm{dL}$ in our optimization protocol.

Preoperative subcutaneous erythropoietin administration is important in Jehovah's Witness patients to stimulate and achieve a higher hemoglobin level. Previous investigators reported systematic use of erythropoietin in patients with a hemoglobin level less than $14 \mathrm{~g} / \mathrm{L} .{ }^{9,12}$ We have observed a transient ischemic attack in a patient who was treated with erythropoietin despite the hemoglobin level reaching $13 \mathrm{~g} / \mathrm{dL}$. The patient had an IABP inserted from the right subclavian artery, and we cannot conclude this event was due to erythropoietin. However, we cannot ignore this event as a coincidence. Thus, we currently discontinue the use of erythropoietin after reaching the hemoglobin level of $13 \mathrm{~g} / \mathrm{dL}$ preoperatively and $11 \mathrm{~g} / \mathrm{dL}$ postoperatively. A clinical practice guideline by the Society of Thoracic Surgeons and the Society of Cardiovascular Anesthesiologist joint task forces suggests a transfusion trigger hemoglobin level of $7 \mathrm{~g} / \mathrm{dL}$ for patients after cardiac surgery. ${ }^{13}$ We observed a mean hemoglobin decrease of $1.5 \mathrm{~g} / \mathrm{dL}$ during the postoperative course. Therefore, we set the threshold for postoperative erythropoietin use at a hemoglobin level of $11 \mathrm{~g} / \mathrm{dL}$ as an appropriate value to maintain a safe hemoglobin margin.

A total of 44 of 137 patients did not achieve a preoperative hemoglobin level of $12 \mathrm{~g} / \mathrm{dL}$ despite iron/vitamin supplementation and erythropoietin application. One factor for the failed optimization was a lower hemoglobin level at 
the initial clinic visit. Another factor was emergency/urgent cases, which did not allow the time to build up hemoglobin in patients. The results of subanalysis performed on nonemergency/urgent patients with hemoglobin levels at the initial clinic visit less than $12 \mathrm{~g} / \mathrm{dL}(\mathrm{N}=41)$ demonstrated that older age and hemodialysis may have an influence on the failure in optimization. Older patients are known to have reduced response to hematopoietic growth factor, ${ }^{14}$ and some patients on dialysis are unresponsive to erythropoietin, ${ }^{15}$ which may be associated with our results of failure.

Intraoperative CPB management also is important when treating Jehovah's Witness patients, as previous reports demonstrated higher mortality in procedures performed on $\mathrm{CPB}$ compared with off $\mathrm{CPB} .{ }^{16}$ Hemodilution during $\mathrm{CPB}$ is an important contributor to intraoperative and postoperative blood losses. The use of retrograde autologous priming minimizes the impact of initial hemodilution. ${ }^{6}$ Ultrafiltration not only provides hemoconcentration but also improves coagulation. ${ }^{17}$ The higher hematocrit and concentration of coagulation factors, and removal of cytokines and toxins are favorable results of the use of ultrafiltration in bloodless CPB surgery. Appropriate use of non-blood-derived topical hemostatic agents and systemic hemostatic agents is beneficial in this patient population. ${ }^{18}$ Antifibrinolytic agents reduce blood loss in patients undergoing surgery by limiting and dissolving clots. We used the serine protease inhibitor aprotinin until its withdrawal from the market in 2008. The lysin analog epsilon-aminocaproic acid was used before and continues to be a mainstay of systemic agents used to control bleeding. There are several studies demonstrating the superiority of aprotinin over lysine analogs in terms of bleeding management, ${ }^{19,20}$ but we did not find a significant difference in bleeding after the cessation of use of aprotinin. This result may emphasize that antifibrinolytic agents are just one of the adjuncts of hemostasis, and the key is meticulous surgical technique and surgical hemostasis, which was proved by a low rate of reexploration for bleeding $(1.5 \%)$ in the present study.

Postoperative hemodynamic support was provided to Jehovah's Witness patients for a longer period of time compared with non-Jehovah's Witness patients (data not shown). In acute anemia, the heart compensates with an increased heart rate and contractility to maintain a normal level of oxygen delivery. Thus, we believe it is important to assist cardiac function to maximize oxygen delivery with inotrope or IABP support, and reduce oxygen consumption with mechanical ventilation support by minimizing the work of breathing. ${ }^{21}$

Providing heart transplantation and LVAD implantation to Jehovah's Witnesses is an important, sensitive issue. We are extremely cautious when selecting these candidates. In addition to the protocol described in the article, we use subclavian IABP to improve their organ functions and physical conditionings. ${ }^{22}$ In the current series, 11 patients underwent heart transplantation. There was 1 hospital death due to donor heart failure that required biventricular LVAD support during the transplant surgery. There were 2 more deaths during follow-up due to cytomegalovirus infection and donor heart rejection. All these causes of death after transplantation are not related to the inability to use blood products. Furthermore, no patient died because of the inability to provide blood products after LVAD implantation. However, the decision to treat these patients with heart transplantation or LVAD implantation remains controversial and requires further discussion.

We excluded salvage cases $(n=7)$ because the purpose of this study was to evaluate the feasibility of our preoperative optimization protocol. In-hospital death was observed in 4 salvage patients $(57.1 \%)$. All these patients demonstrated preoperative hemodynamic collapse and were associated with massive acute myocardial infarction $(\mathrm{n}=2)$, unstable angina $(\mathrm{n}=2)$, acute type A aortic dissection $(n=2)$, or third-time reoperation for prosthetic valve dysfunction $(n=1)$. The analysis for the cohort including these 7 cases demonstrated that the factors associated with mortality were nonelective operation, suboptimal hemoglobin, and chronic kidney injury on univariate analysis (Table E6).

Our outcomes also provide incremental evidence to the dispute over adverse outcomes associated with a lower hematocrit and liberal use of blood transfusions in patients undergoing cardiac surgery. ${ }^{23}$ Preoperative anemia has been implied as a predictor of morbidity and mortality after cardiac surgery, ${ }^{24,25}$ whereas others argue that the low hematocrit is just the threshold for blood transfusion and the transfusion itself is causing the harm. ${ }^{23,26}$ Because our data are obtained from bloodless cardiovascular surgery, it provides support to the fact that preoperative anemia is an important independent factor associated with postoperative adverse outcomes.

\section{Study Limitations}

First, this is a single-center nonrandomized retrospective study. Second, the preoperative target hemoglobin level of $12 \mathrm{~g} / \mathrm{dL}$ is based on our data and is institute-specific, and thus may not be appropriate for use in other institutions. Third, most of our Jehovah's Witness patients were referred to our service from outside hospitals and might have had selection biases by their physicians to have better outcomes. Nevertheless, approximately half the patients had been declined for surgical treatment at other hospitals and were high-risk surgical candidates.

\section{CONCLUSIONS}

Despite the complexity of the patients and total avoidance of blood products, cardiovascular surgery in 
Jehovah's Witness patients was associated with acceptable surgical outcomes, especially if they were electively completed optimization. Our Jehovah's Witnesses' optimization protocol targeting a hemoglobin level more than $12 \mathrm{~g} / \mathrm{dL}$ seemed appropriate to reduce postoperative adverse events at The University of Chicago Medicine.

\section{Conflict of Interest Statement}

Outside the submitted work, Dr Jeevanandam is a Scientific Advisor of Thoratec, HeartWare, and ReliantHeart. Dr Uriel is a Scientific Advisor of Thoratec, HeartWare, and Abiomed. All other authors have nothing to disclose with regard to commercial support.

\section{References}

1. Watch Tower Bible and Tract Society of Pennsylvania. Questions from readers. Watchtower. 2000; June 15:29-31.

2. Levey AS, Coresh J, Greene T, Marsh J, Stevens LA, Kusek JW, et al. Expressing the modification of diet in renal disease study equation for estimating glomerular filtration rate with standardized serum creatinine values. Clin Chem. 2007;53: 766-72.

3. Bellomo R, Ronco C, Kellum JA, Mehta RL, Palevsky P. Acute Dialysis Quality Initiative. Acute renal failure - definition, outcome measures, animal models, fluid therapy and information technology needs: the Second International Consensus Conference of the Acute Dialysis Quality Initiative (ADQI) Group. Crit Care. 2004;8:R204-12.

4. Habib RH, Zacharias A, Schwann TA, Riordan CJ, Durham SJ, Shah A. Adverse effects of low hematocrit during cardiopulmonary bypass in the adult: should current practice be changed? J Thorac Cardiovasc Surg. 2003;125:1438-50.

5. Murphy GS, Szokol JW, Nitsun M, Alspach DA, Avram MJ, Vender JS, et al. Retrograde autologous priming of the cardiopulmonary bypass circuit: safety and impact on postoperative outcomes. J Cardiothorac Vasc Anesth. 2006;20:156-61.

6. Rubens FD, Boodhwani M, Mesana T, Wozny D, Well G, Nathan HJ. The cardiotomy trial: a randomized, double-blind study to assess the effect of processing of shed blood during cardiopulmonary bypass on transfusion and neurocognitive function. Circulation. 2007;116(11 Suppl):I89-97.

7. Cooley DA, Crawford ES, Howell JF, Beall AC Jr. Open heart surgery in Jehovah's Witnesses. Am J Cardiol. 1964;13:779-81.

8. Lewis CT, Murphy MC, Cooley DA. Risk factors for cardiac operations in adult Jehovah's Witnesses. Ann Thorac Surg. 1991;51:448-50.

9. Vaislic CD, Dalibon N, Ponzio O, Jugan E, Lagneau F, Abbas P, et al. Outcomes in cardiac surgery in 500 consecutive Jehovah's Witness patients: 21 year experience. J Cardiothorac Surg. 2012;7:95.

10. Pattakos G, Koch CG, Brizzio ME, Batizy LH, Sabik JF III, Blackstone EH, et al. Outcome of patients who refuse transfusion after cardiac surgery: a natural experiment with severe blood conservation. Arch Intern Med. 2012;172: 1154-60.

11. Vonk AB, Meesters MI, van Dijk WB, Eijsman L, Romijn JW, Jansen E, et al. Ten-year patterns in blood product utilization during cardiothoracic surgery with cardiopulmonary bypass in a tertiary hospital. Transfusion. 2014;54 2608-16.

12. Jassar AS, Ford PA, Haber HL, Isidro A, Swain J, Bavaria JE, et al. Cardiac surgery in Jehovah's Witness patients: ten-year experience. Ann Thorac Surg. 2012 93:19-25.

13. Society of Thoracic Surgeons Blood Conservation Guideline Task Forces, Ferraris VA, Ferraris SP, Saha SP, Hessel EA II, Haan CK, Royston BD, et al Perioperative blood transfusion and blood conservation in cardiac surgery: the Society of Thoracic Surgeons and the Society of Cardiovascular Anesthesiologists clinical practice guideline. Ann Thorac Surg. 2007;83(5 Suppl):S27-86.

14. Berkahn L, Keating A. Hematopoiesis in the elderly. Hematology. 2004;9: 159-63.

15. Fukuma S, Yamaguchi T, Hashimoto S, Nakai S, Iseki K, Tsubakihara Y, et al. Erythropoiesis-stimulating agent responsiveness and mortality in hemodialysis patients: results from a cohort study from the dialysis registry in Japan. Am J Kid ney Dis. 2012;59:108-16.

16. Henderson AM, Maryniak JK, Simpson JC. Cardiac surgery in Jehovah's Wit nesses. A review of 36 cases. Anaesthesia. 1986;41:748-53.

17. Boodhwani M, Hamilton A, de Varennes B, Mesana T, Williams K, Wells GA, et al. A multicenter randomized controlled trial to assess the feasibility of testing modified ultrafiltration as a blood conservation technology in cardiac surgery. $J$ Thorac Cardiovasc Surg. 2010;139:701-6.

18. Spahn DR, Goodnough LT. Alternatives to blood transfusion. Lancet. 2013;381 $1855-65$.

19. Beckerman Z, Shopen Y, Alon H, Cohen O, Nir RR, Adler Z, et al. Coronary artery bypass grafting after aprotinin: are we doing better? J Thorac Cardiovasc Surg. 2013;145:243-8.

20. Martin K, Gertler R, Liermann H, Mayr NP, MacGuill M, Schreiber C, et al. Switch from aprotinin to epsilon-aminocaproic acid: impact on blood loss, transfusion, and clinical outcome in neonates undergoing cardiac surgery. $\mathrm{Br} J$ Anaesth. 2011;107:934-9.

21. Posluszny JA Jr, Napolitano LM. How do we treat life-threatening anemia in a Jehovah's Witness patient? Transfusion. 2014:54:3026-34.

22. Tanaka A, Tuladhar SM, Onsager D, Asrfaw Z, Ota T, Juricek C, et al. The subclavian intra-aortic balloon pump-a compelling bridge device for advanced heart failure. Ann Thorac Surg. July 28, 2015 [Epub ahead of print].

23. Speiss BD. Transfusion and outcome in heart surgery. Ann Thorac Surg. 2002;74 986-7.

24. Williams ML, He X, Rankin JS, Slaughter MS, Gammie JS. Preoperative hematocrit is a powerful predictor of adverse outcomes in coronary artery bypass graft surgery: a report from the Society of Thoracic Surgeons Adult Cardiac Surgery Database. Ann Thorac Surg. 2013;96:1628-34.

25. Loor G, Li L, Sabik JF III, Rajeswaran J, Blackstone EH, Koch CG. Nadir hematocrit during cardiopulmonary bypass: end-organ dysfunction and mortality. $J$ Thorac Cardiovasc Surg. 2012;144:654-62.

26. Surgenor SD, DeFoe GR, Fillinger MP, Likosky DS, Groom RC, Clark C, et al Intraoperative red blood cell transfusion during coronary artery bypass graft surgery increases the risk of postoperative low-output heart failure. Circulation. 2006;114(1 Suppl):I43-8.

Key Words: blood conservation, cardiopulmonary bypass, cardiovascular surgery, Jehovah's Witness 
TABLE E1. Perioperative optimization protocol for Jehovah's Witnesses

\begin{tabular}{|c|c|}
\hline Protocols & Procedures \\
\hline \multicolumn{2}{|l|}{ Preoperative } \\
\hline Target hemoglobin level $12 \mathrm{~g} / \mathrm{dL}$ & $\begin{array}{l}\text { PO iron } 60 \mathrm{mg} \text { (ferrous sulfate } 325 \mathrm{mg} \text { ) } 3 \text { times per day or IV iron sucrose } 2 \mathrm{mg} / \mathrm{kg} / \mathrm{d} \\
\text { PO folic acid } 1 \mathrm{mg} \text { once per day* } \\
\text { PO cobalamin } 1000 \mu \mathrm{g} \text { twice per day* } \\
\text { SC EPO } 250-500 \mathrm{U} / \mathrm{kg} \text { every } 48 \mathrm{~h} \text { or IV EPO } 200 \mathrm{U} / \mathrm{kg} \text { every } 24 \mathrm{~h}^{*}\end{array}$ \\
\hline Withholding antiplatelets/supplements & $\begin{array}{l}\text { Aspirin ( } 5 \mathrm{~d} \text { prior }) \\
\text { Clopidogrel (10 d prior) } \\
\text { Vitamin E, fish oil ( } 7 \mathrm{~d} \text { prior }) \\
\text { Turmeric, ginger ( } 7 \text { d prior) }\end{array}$ \\
\hline \multicolumn{2}{|l|}{ Intraoperative } \\
\hline Blood conservation during $\mathrm{CPB}$ & $\begin{array}{l}\text { Retrograde priming (avoiding hemodilution) } \\
\text { Autologous whole blood sequestration (preserving coagulation factors) } \dagger \\
\text { Pump sucker use during CPB (preserving platelet and coagulation factors, avoid Cell Saver } \\
\text { [Haemonetics Corp, Braintree, Mass]) } \\
\text { Cool to core temperature of } 34^{\circ} \mathrm{C} \text { and rewarm to } 37^{\circ} \mathrm{C} \text { before the termination of CPB }\end{array}$ \\
\hline \multicolumn{2}{|l|}{ Hemostasis adjuncts (as needed) } \\
\hline Nonblood derivatives & $\begin{array}{l}\text { Hemasorb (Abyrx Inc, Irvington, NY) (hemostasis of sternum) } \\
\text { Coseal (Baxter Healthcare Corp, Deerfield, Ill) (sealant) } \\
\text { EACA, aprotinin } \uparrow \text { recombinant factor VII }\end{array}$ \\
\hline Blood derivatives $\S$ & Topical fibrin, thrombin \\
\hline Surgical techniques & Anastomosis reinforcement (eg, Teflon gasket for LVAD outflow tract) \\
\hline \multicolumn{2}{|l|}{ Postoperative } \\
\hline Vitals & $\begin{array}{l}\text { Keep at normothermia } \\
\text { Avoid high blood pressure } \\
\text { Longer hemodynamic support (with inotropes, IABP, or mechanical ventilation support) }\end{array}$ \\
\hline Blood test & $\begin{array}{l}\text { Elimination of routine blood tests } \\
\text { Minimal volume of blood (pediatric tubes) }\end{array}$ \\
\hline $\begin{array}{l}\text { Iron/vitamin/EPO supplementation } \\
\quad(\text { target hemoglobin }>10 \mathrm{~g} / \mathrm{dL})\end{array}$ & $\begin{array}{l}\text { IV iron sucrose } 2 \mathrm{mg} / \mathrm{kg} / \mathrm{d} \\
\text { PO vitamin (continuation of preoperative prescription) } \\
\text { SC EPO 250-500 U/kg every } 48 \mathrm{~h} \text { or IV EPO 200-300 U/kg every } 24 \mathrm{~h}^{*}\end{array}$ \\
\hline
\end{tabular}

TABLE E2. Preoperative risk factors for prolonged ventilation ( $>48$ hours)

\begin{tabular}{|c|c|c|c|c|c|c|}
\hline & \multicolumn{3}{|c|}{ Univariate } & \multicolumn{3}{|c|}{ Multivariate } \\
\hline & OR & $95 \% \mathrm{CI}$ & $P$ value & OR & $95 \% \mathrm{CI}$ & $P$ value \\
\hline Age $>65 y$ & 1.42 & $0.36-5.52$ & .736 & & & \\
\hline Female & 0.34 & $0.07-1.72$ & .968 & & & \\
\hline BMI $>30 \mathrm{~kg} / \mathrm{m}^{2}$ & 9.96 & $1.21-82.01$ & .013 & 13.55 & $2.02-278.39$ & .005 \\
\hline $\mathrm{Hb}<12.0 \mathrm{~g} / \mathrm{dL}$ & 8.61 & $1.71-43.38$ & .005 & 7.31 & $1.42-58.07$ & .016 \\
\hline Diabetes mellitus & 0.71 & $0.17-2.96$ & .737 & & & \\
\hline Cerebrovascular disease & 0 & & .606 & & & \\
\hline Chronic lung disease & 1.53 & $0.36-6.49$ & .691 & & & \\
\hline $\mathrm{eGFR}<60 \mathrm{~mL} / \mathrm{min} / 1.73 \mathrm{~m}^{2}$ & 6.68 & $1.33-33.54$ & .013 & 3.56 & $.69-27.26$ & .133 \\
\hline On dialysis & 4.94 & $0.86-28.32$ & .109 & & & \\
\hline $\mathrm{sPAP}>55 \mathrm{~mm} \mathrm{Hg}$ & 1.79 & $0.42-7.60$ & .423 & & & \\
\hline LVEF $<40 \%$ & 0.73 & $0.19-2.84$ & .647 & & & \\
\hline NYHA IV & 3.45 & $0.82-14.43$ & .089 & 5.34 & $1.09-33.38$ & .038 \\
\hline IABP support & 0.57 & $0.07-4.79$ & 1.000 & & & \\
\hline Resternotomy & 1.30 & $0.25-6.69$ & .668 & & & \\
\hline Emergency/urgent & 1.38 & $0.33-5.84$ & .702 & & & \\
\hline
\end{tabular}

$B M I$, Body mass index; $C I$, confidence interval; $e G F R$, estimated glomerular filtration rate; $H b$, hemoglobin; $I A B P$, intra-aortic balloon pump; $L V E F$, left ventricular ejection fraction; NYHA, New York Heart Association; $O R$, odds ratio; $S P A P$, systolic pulmonary artery pressure. 
TABLE E3. Preoperative risk factors for postoperative acute kidney injury

\begin{tabular}{|c|c|c|c|c|c|c|}
\hline & \multicolumn{3}{|c|}{ Univariate } & \multicolumn{3}{|c|}{ Multivariate } \\
\hline & OR & $95 \% \mathrm{CI}$ & $P$ value & OR & $\mathbf{9 5} \% \mathrm{CI}$ & $P$ value \\
\hline Age $>65 y$ & 2.78 & $1.15-6.70$ & .020 & 2.27 & $0.85-6.45$ & .104 \\
\hline Female & 0.88 & $0.38-2.04$ & .968 & & & \\
\hline $\mathrm{BMI}>30 \mathrm{~kg} / \mathrm{m}^{2}$ & 2.13 & $0.91-4.98$ & .077 & 2.11 & $0.74-6.35$ & .163 \\
\hline $\mathrm{Hb}<12.0 \mathrm{~g} / \mathrm{dL}$ & 5.60 & $2.30-13.59$ & $<.0001$ & 3.80 & $1.46-10.09$ & .006 \\
\hline Diabetes mellitus & 2.35 & $1.01-5.46$ & .043 & 1.64 & $0.57-4.71$ & .355 \\
\hline Cerebrovascular disease & 2.61 & $0.84-8.08$ & .011 & & & \\
\hline Chronic lung disease & 1.45 & $0.58-3.62$ & .427 & & & \\
\hline $\mathrm{eGFR}<60 \mathrm{~mL} / \mathrm{min} / 1.73 \mathrm{~m}^{2}$ & 2.86 & $1.21-6.70$ & .013 & 1.58 & $0.59-4.17$ & .360 \\
\hline $\mathrm{sPAP}>55 \mathrm{~mm} \mathrm{Hg}$ & 1.05 & $0.40-2.77$ & .919 & & & \\
\hline LVEF $<40 \%$ & 0.97 & $0.42-2.22$ & .939 & & & \\
\hline NYHA IV & 1.50 & $0.65-3.45$ & .340 & & & \\
\hline IABP support & 3.20 & $1.23-8.28$ & .013 & 3.94 & $1.26-12.76$ & .019 \\
\hline Resternotomy & 0.82 & $0.28-2.43$ & .724 & & & \\
\hline Emergency/urgent & 1.91 & $0.79-4.60$ & .146 & & & \\
\hline
\end{tabular}

$B M I$, Body mass index; $C I$, confidence interval; $e G F R$, estimated glomerular filtration rate; $H b$, hemoglobin; $I A B P$, intra-aortic balloon pump; $L V E F$, left ventricular ejection fraction; NYHA, New York Heart Association; $O R$, odds ratio; $S P A P$, systolic pulmonary artery pressure.

TABLE E4. Optimization of elective patients with hemoglobin $<12 \mathrm{~g} / \mathrm{dL}$ at the initial clinic visit

\begin{tabular}{|c|c|c|c|c|}
\hline & Failure $(n=24)$ & Success $(n=17)$ & OR $(95 \%$ CI $)$ & $P$ value \\
\hline Age $>65 y$ & $12(50.0 \%)$ & $4(23.5 \%)$ & $3.33(0.82-12.88)$ & .087 \\
\hline Male & $14(58.3 \%)$ & $8(47.1 \%)$ & $1.59(0.45-5.56)$ & .476 \\
\hline $\operatorname{BSA}\left(\mathrm{m}^{2}\right)$ & $2.0(1.9-2.2)$ & $2.1(1.8-2.3)$ & $0.45(0.06-2.14)$ & .615 \\
\hline BMI $\left(\mathrm{kg} / \mathrm{m}^{2}\right)$ & $30.4(24.7-38.4)$ & $32.5(25.5-37.1)$ & $1.00(0.98-1.03)$ & .483 \\
\hline Hemoglobin $(\mathrm{g} / \mathrm{dL})$ at the initial clinic visit & $10.6(9.4-11.3)$ & $10.3(9.8-11.5)$ & $0.83(0.41-1.58)$ & .686 \\
\hline Diabetes mellitus & $12(50.0 \%)$ & $7(41.2 \%)$ & $1.43(0.41-5.00)$ & .577 \\
\hline Chronic lung disease & $8(33.3 \%)$ & $6(37.5 \%)$ & $0.83(0.22-3.12)$ & .787 \\
\hline Chronic kidney disease & $15(62.5 \%)$ & $7(41.2 \%)$ & $2.38(0.67-8.49)$ & .177 \\
\hline On dialysis & $5(20.8 \%)$ & $0(0.0 \%)$ & 0 & .053 \\
\hline Severe PAH & $5(20.8 \%)$ & $7(41.2 \%)$ & $0.38(0.09-1.49)$ & .183 \\
\hline LVEF (\%) & $55(24-60)$ & $42(21-60)$ & $1.01(0.98-1.04)$ & .774 \\
\hline NYHA class IV & $7(29.2 \%)$ & $7(41.2 \%)$ & $0.58(0.16-2.17)$ & .424 \\
\hline IABP support & $6(25.0 \%)$ & $2(11.8 \%)$ & $2.50(0.44-14.25)$ & .433 \\
\hline Inotrope support & $4(16.7 \%)$ & $4(23.5 \%)$ & $1.38(0.37-5.10)$ & .737 \\
\hline
\end{tabular}

Data are presented as median (IQR) or $\mathrm{n}(\%)$. Chronic kidney disease is eGFR $<60 \mathrm{~mL} / \mathrm{min} / 1.73 \mathrm{~m}^{2} . B M I$, Body mass index; $B S A$, body surface area; $C I$, confidence interval; $I A B P$, intra-aortic balloon pump; $L V E F$, left ventricular ejection fraction; $N Y H A$, New York Heart Association; $O R$, odds ratio; PAH, pulmonary artery hypertension.

TABLE E5. Postoperative complications: Aprotinin versus no aprotinin era

\begin{tabular}{|c|c|c|c|c|}
\hline Variables & Aprotinin era $(\mathbf{n}=38)$ & Post-aprotinin era $(\mathbf{n}=99)$ & OR $(95 \%$ CI $)$ & $P$ value \\
\hline Reexploration for bleeding & $1(2.6 \%)$ & $1(1.0 \%)$ & $2.65(0.16-43.45)$ & .479 \\
\hline In-hospital mortality & $2(5.3 \%)$ & $7(7.1 \%)$ & $0.73(0.15-3.68)$ & 1.000 \\
\hline Myocardial infarction & $0(0.0 \%)$ & $0(0.0 \%)$ & 0 & 1.000 \\
\hline Acute kidney injury & $6(15.8 \%)$ & $23(23.2 \%)$ & $0.63(0.23-1.71)$ & .340 \\
\hline Stroke & $1(2.6 \%)$ & $2(2.0 \%)$ & $1.31(0.11-14.9)$ & 1.000 \\
\hline
\end{tabular}

Data are presented as $\mathrm{n}(\%)$. CI, Confidence interval; OR, odds ratio. 
TABLE E6. Preoperative factors associated with in-hospital mortality $(N=144$, with salvage cases)

\begin{tabular}{|c|c|c|c|c|c|c|}
\hline & \multicolumn{3}{|c|}{ Univariate } & \multicolumn{3}{|c|}{ Multivariate } \\
\hline & OR & $95 \% \mathrm{CI}$ & $P$ value & OR & $95 \%$ CI & $P$ value \\
\hline Age $>65 y$ & 1.38 & $0.44-4.39$ & .582 & & & \\
\hline Female & 1.51 & $0.48-4.74$ & .478 & & & \\
\hline $\mathrm{BMI}>30 \mathrm{~kg} / \mathrm{m}^{2}$ & 0.52 & $0.15-1.79$ & .296 & & & \\
\hline $\mathrm{Hb}<12.0 \mathrm{~g} / \mathrm{dL}$ & 5.42 & $1.58-18.66$ & .010 & 3.99 & $0.99-20.20$ & .052 \\
\hline Diabetes mellitus & 2.42 & $0.74-7.78$ & .130 & & & \\
\hline Cerebrovascular disease & 2.05 & $0.51-8.19$ & .389 & & & \\
\hline Chronic lung disease & 1.38 & $0.40-4.77$ & .737 & & & \\
\hline $\mathrm{eGFR}<60 \mathrm{~mL} / \mathrm{min} / 1.73 \mathrm{~m}^{2}$ & 6.52 & $1.71-24.88$ & .002 & 3.86 & $0.93-20.00$ & .063 \\
\hline $\mathrm{sPAP}>55 \mathrm{~mm} \mathrm{Hg}$ & 4.58 & $1.42-14.75$ & .012 & 2.42 & $0.60-9.56$ & .210 \\
\hline $\mathrm{LVEF}<40 \%$ & 1.44 & $0.45-4.64$ & .539 & & & \\
\hline NYHA IV & 1.76 & $0.56-5.53$ & .328 & & & \\
\hline IABP support & 0.83 & $0.17-3.97$ & 1.000 & & & \\
\hline Resternotomy & 1.36 & $0.35-5.33$ & .708 & & & \\
\hline Nonelective & 5.14 & $1.46-18.08$ & .009 & 4.07 & $1.05-17.79$ & .042 \\
\hline
\end{tabular}

$B M I$, Body mass index; $C I$, confidence interval; $e G F R$, estimated glomerular filtration rate; $H b$, hemoglobin; $I A B P$, intra-aortic balloon pump; $L V E F$, left ventricular ejection fraction; NYHA, New York Heart Association; $O R$, odds ratio; $s P A P$, systolic pulmonary artery pressure. 